\title{
POLÍTICAS DE INDUÇÃO À MUDANÇA NA EDUCAÇÃO DOS TRABALHADORES DA SAÚDE: MATRIZES DISCURSIVAS DO CAMPO
}

\author{
POLICIES TO INDUCE THE CHANGE IN THE HEALTH WORKERS \\ EDUCATION: MATRICES DISCURSIVE FIELD
}

Tiago José Silveira Teófilo

Enfermeiro, mestre em clínica médica, Servidor da Hospital Universitário Lauro Wanderley, Universidade Federal da Paraíba.

E-mail: tiagojosest@yahoo.com.br

\section{Rossana Staevie Baduy}

Doutora em Ciências pelo programa de Pós-Graduação em Clínica Médica da UFRJ. Aposentada pela Univerdidade Estadual de Lonfrina. Atua como gestora da Secretaria Municipal de Saúde de Londrina-PR

E-mail: robaduy@gmail.com

\section{Nereida Lúcia Palko dos Santos}

Professora da Universidade Federal do Rio de Janeiro - Escola de Enfermagem Ana Nery. Doutora em Enfermagem pela Escola de Enfermagem Ana Nery da UFRJ.

E-mail: nereida@ufrj.br.

\section{Resumo}

Buscou-se compreender as matrizes discursivas evidenciadas nas políticas de indução à mudança na educação dos trabalhadores da saúde no Brasil. O Projeto de Incentivo a Mudanças Curriculares em Cursos de Medicina, o Programa de Reorientação da Formação Profissional em Saúde e o Programa de Educação pelo Trabalho para a Saúde derivam da corrente Vigilância à Saúde e são marcados pela centralidade na atenção primária, epidemiologia crítica e determinação social do processo saúdeenfermidade-atenção. A Política de Educação e Desenvolvimento para o SUS, a Aprender-SUS: O SUS e os cursos de graduação na área da saúde e o Projeto Vivências e Estágios na Realidade do SUS do Brasil estão ligados à corrente Em Defesa da Vida. Aproximam-se pela noção de atendimento às necessidades de saúde com desenvolvimento de autonomia das pessoas e pelas categorias humanização e sistema de saúde usuário-centrados.

Palavras-chave: Saúde Coletiva. Política de Saúde. Política de Educação Superior. Formação de Profissionais de Saúde. 


\section{Abstract}

We sought to understand the discursive matrices in the policies to induce the change in the health workers education in Brazil. The Projeto de Incentivo a Mudanças Curriculares em Cursos de Medicina, the Programa de Reorientação da Formação Profissional em Saúde and Programa de Educação pelo Trabalho para a Saúde are derived from the current Health Surveillance and are marked by the centrality in primary health care, epidemiology criticism and social determinants of the healthdisease-care. The Política de Educação e Desenvolvimento para o SUS, the AprenderSUS: O SUS e os cursos de graduação na área da saúde and Projeto Vivências e Estágio na Realidade do SUS do Brasil are connected to the current theoretical Defending Your Life. The assumptions that are approaching the notion of meeting the health needs of people with developing their autonomy and humanization and health system usercentered categories.

Keywords: Public Health. Health Policies. Higher Education Policy. Education, Health Professionals.

\section{Introdução}

A formação em nível de graduação dos trabalhadores da saúde tem sido habitada por vetores que mobilizam forças por meio de diversas estratégias político-pedagógicas. No Brasil, há políticas públicas e movimentos sociais, corporativos e acadêmicos com intencionalidade de influenciar, e que, disputam a educação dos trabalhadores da área. Observam-se diferentes interesses, desde a atualização permanente na utilização de aparelhos e medicamentos e realização de procedimentos técnicos sofisticados, até a condução da formação à luz das necessidades de saúde, das práticas de humanização e da realidade social dos brasileiros.

Os aspectos sócio históricos das iniciativas de mudança na educação dos trabalhadores da saúde, desenvolvidas nos últimos quarenta anos no Brasil, sugerem haver diversas formulações teóricas e o desenvolvimento de modelos, diretrizes, projetos e políticas para ocampo. Em resumo, os principais exemplos são os Projetos Integração Docente-Assistencial (IDA) e Uma nova iniciativa na formação dos profissionais de saúde: união com a comunidade (UNI), que conformaram a Rede Unida; os arranjos desenvolvidos pelas profissões, como a Comissão Interinstitucional de Avaliação do Ensino Médico na Medicina e o Movimento Participação na Enfermagem; a construção conjunta das Diretrizes Curriculares Nacionais (DCN) para os cursos universitários da área da saúde, além de políticas públicas principalmente de caráter nacional. ${ }^{1,2}$

No que diz respeito às estratégias governamentais, o artigo 200 da Constituição Federal de 1988 deliberou que é dever do Estado ordenar a formação na área da saúde. A Lei Orgânica da Saúde de 1990 estabeleceu que todos os entes federativos devem participar na formulação e execução da política de formação e desenvolvimento dos trabalhadores para a saúde no Brasil. No entanto, as ações de governo na área só se desenvolverão com volume significativo de recursos entre o final da década de 1990 e início dos anos 2000. Nesse percurso, a criação da Secretaria de Gestão do Trabalho e da Educação na Saúde e do Departamento de Gestão da Educação na Saúde no âmbito do Ministério da Saúde, em 2003, foi um marco importante para institucionalização destas ações. ${ }^{3,4,5}$

As formulações acerca do ensino das profissões da saúde são atravessadas 
por diversas tensões paradigmáticas produzindo uma variedade de propostas teóricas e de novas experimentações no modo de formar os trabalhadores da saúde. Os discursos e práticas produzidos no mundo do ensino da saúde são fabricados a partir de disputas políticas e de processos dinâmicos e descontínuos de produção de saber e prática. A análise de matrizes discursivas, a partir da ideia do discurso como acontecimento em Foucault ${ }^{6}$, busca aproveitar as chances de apreender nos enunciados seus possíveis jogos de relações e dinamismo. Nesse ínterim, buscou-se decifrar as relações presentes na produção dos discursos a partir das construções teóricas de políticas, programas e projetos que incentivam mudanças na formação dos trabalhadores de saúde no âmbito do Sistema Único de Saúde (SUS).

Tal tarefa é desafiadora diante da imensa produção discursiva na contemporaneidade. Contudo, entendese que existem possibilidades de lograr-se, por meio de recortes da produção de alguns pesquisadores, em paralelo aos enunciados de estratégias políticas, compreenderemse as matrizes discursivas que são mais evidenciadas na produção acadêmica e nos projetos e práticas em disputa.

Nesse ínterim, observa-se que existem eixos discursivos dos quais emergem as propostas indutoras de mudança no ensino de graduação dos trabalhadores da saúde, as quais se aproximam de dois campos de produções discursivas, a saber: a Saúde Coletiva brasileira e os núcleos ou corporações profissionais. Para o presente artigo, no entanto, apenas as matrizes discursivas da Saúde Coletiva serão discutidas.

Sem pretensão de esgotar o debate, este texto objetivou discutir quais as produções discursivas que transitam nos modelos de educação dos trabalhadores de saúde no Brasil no âmbito da Saúde Coletiva. Como justificativa, entende-se como relevante, a mobilização de esforços para analisarem-se as ações que têm demandado grande esforço e recursos do Estado brasileiro para a ordenação da formação dos profissionais de saúde.

\section{Aspectos metodológicos}

Com intuito de caracterizar as políticas, programas e projetos de âmbito nacional do campo, foram acessadas fontes secundárias das principais publicações oficiais, como livros, relatórios, portarias, editais e outros materiais publicados eletronicamente pelo Ministério da Saúde (MS), especialmente da Secretaria de Gestão do Trabalho e da Educação na Saúde, referentes ao período de 2001 a 2013. O recorte temporal aqui estabelecido justifica-se pela intensificação da produção discursiva do Governo com intuito de intervir na formação dos trabalhadores da saúde, consolidados a partir da década de 2000.

No presente artigo, como parte da análise da literatura da área, após descrição das principais propostas do MS, serão apresentadas as matrizes discursivas elaboradas por meio de recortes de importantes publicações de alguns pesquisadores no âmbito na saúde coletiva brasileira, a saber: Mendes, Campos, Merhy, Almeida-Filho, Teixeira, Ceccim, e Feuerwerker.

As propostas governamentais do campo em questão estão em boa parte intimamente relacionadas a duas importantes correntes de pensamento da Saúde Coletiva, identificadas e nomeadas por pesquisadores da área que são: Vigilância à Saúde (VISAU) e Em Defesa da Vida (DV). ${ }^{7,8}$ Portanto, após descreverem-se as principais características dos programas, projetos e políticas da área, desenvolvidos pelo MS no decorrer dos anos 2000, buscou- 
se suas aproximações teóricas com estas correntes.

Em relação aos aspectos éticos, a pesquisa foi aprovada pelo Comitê de Ética em Pesquisa do Hospital Universitário Clementino Fraga Filho da UFRJ com protocolo número 070/11.

\section{Resultados e Discussão}

A Saúde Coletiva que se desenvolve nas décadas de $1970-80$ no Brasil privilegiava, à época, o enfrentamento de aspectos macrossociais que determinam o processo saúde-doença. Buscava discutir a necessidade de mudança no modo de produção capitalista com intuito de garantira equidade na distribuição de bens e serviços, porém, ainda sem adentrar nos aspectos microsociais ou micropolíticos. ${ }^{9}$ Dessa forma, percebendo-se tal limitação, no decorrer dos anos 1990, algumas correntes se desenvolveram com o intuito de propor alternativas para a mudança do processo de trabalho em saúde, com destaque para a Vigilância à Saúde e Em Defesa da Vida, que se fortaleceram em âmbito nacional a ponto de influenciar as produções de políticas públicas.

Nesse contexto, muitas estratégias governamentais, com intuito de avançar na construção do SUS, passarão a basearse em matrizes discursivas de correntes da Saúde Coletiva. Observou-se que o Projeto de Incentivo a Mudanças Curriculares em Cursos de Medicina (Promed), o Programa de Reorientação da Formação Profissional em Saúde (Pró-Saúde) e o Programa de Educação pelo Trabalho para a Saúde (PETSaúde) estão intimamente relacionados com a corrente VISAU. Já a Política de Educação e Desenvolvimento para o SUS (EducarSUS), a Aprender-SUS: O SUS e os cursos de graduação na área da saúde (Aprender-
SUS), e o Projeto Vivências e Estágios na Realidade do SUS do Brasil (VER-SUS/Brasil) correlacionam-se com a corrente DV. Tais propostas não serão situadas em linearidade cronológica, mas pela articulação da produção de enunciados que definem suas proposições teórico-práticas.

Vale ressaltar que as aproximações encontradas devem ser pensadas no contexto da descontinuidade dos governos, na polifonia conceitual e nas disputas entre os próprios pesquisadores identificados como pertencentes à mesma corrente. Portanto, não há aplicação de modelos teóricos na sua pureza, e sim um conjunto de ações desenvolvidas por sujeitos de diferentes contextos em disputa, que utilizam as matrizes da Saúde Coletiva para produzir propostas governamentais e provocar mudança na educação dos trabalhadores da saúde.

\section{O Promed, Pró-Saúde, PET-Saúde e a corrente da Vigilância à Saúde}

Cronologicamente 0 primeiro programa desenvolvido pelo Ministério da Saúde na área em análise foi o Programa de Incentivo às Mudanças Curriculares nos Cursos de Graduação em Medicina, lançado em 2001. Baseou-se na construção de estratégias de mudança na formação dos médicos por meio do oferecimento de cooperação técnica e/ou operacional às escolas de graduação em medicina com intuito de adotar processos de mudança nos currículos. O enfoque eram as necessidades de saúde da população e do SUS e a programação de estágios nos hospitais universitários e em toda a rede de serviços, possibilitando a formação de médicos com competência geral, essencial à ampliação de programas de atenção 
primária à saúde, como o Programa Saúde da Família, designado nos últimos anos de Estratégia Saúde da Família (ESF). O Projeto recomendou as seguintes mudanças pedagógicas: ênfase na medicina preventiva com valorização do conceito de saúde em detrimento da doença; humanização do atendimento com formação de base ética sólida; incentivo ao ingresso dos futuros médicos em ações da atenção primária à saúde e promoção da abertura dos serviços universitários à demanda do SUS. A proposta do Promed se fundamentou em três eixos principais: orientação teórica, abordagem pedagógica e cenário de práticas. Para cada um desses eixos foram descritos vetores, com os caminhos para alcançá-los, nos quais havia o detalhamento de três estágios. Os cursos enviaram suas propostas situando em que estágio consideravam estar no momento, para cada vetor proposto. ${ }^{10,11}$

Aos moldes do Promed, em 2005, o MS, em parceria com o Ministério da Educação (MEC), lança nova proposta para incentivar mudanças nos cursos já participantes da primeira versão, incluindo-se graduações em enfermagem e odontologia. Trata-se do Programa de Reorientação da Formação Profissional em Saúde. A nova proposta tem intuito de incentivar a transformação do processo de formação, geração de conhecimento e prestação de serviços à população a partir da abordagem integral do processo saúdedoença. Os enunciados do Programa são semelhantes ao do Promed, sendo dada maior ênfase à integração ensino-serviço na atenção primária à saúde. ${ }^{12}$

O Programa contemplou inicialmente os cursos de medicina, enfermagem e odontologia adotando como justificativa a inserção destes profissionais nas equipes mínimas da ESF. Tal escolha foi defendida a partir da ideia de que a abordagem interdisciplinar e o trabalho em equipes multiprofissionais raramente são explorados pelas instituições formadoras na graduação, o que se reproduz nas equipes de saúde, resultando na ação isolada de cada profissional e na sobreposição das ações de cuidado e sua fragmentação. ${ }^{13}$

Em 2007, no entanto, a partir da pressão exercida pelas outras profissões de saúde, o Programa lança nova chamada de propostas abrangendo todos os cursos de graduação da área. Na versão de 2005, mantida com as mesmas características em 2007, o Programa utiliza-se da metodologia de aplicação do Promed, adotando como estratégia a perspectiva de que os principais eixos que devem ser reorientados simultaneamente na formação são a orientação teórica, os cenários de prática e a orientação pedagógica. ${ }^{12,14,15}$

Em relação ao Promed, são observadas algumas alterações nas novas propostas, como a inclusão do vetor determinantes de saúde e doença no eixo orientação teórica. O eixo propõe que o estágio mais avançado ocorre quando se dá importância equivalente aos determinantes da saúde e da doença, procurando, tanto na abordagem do conhecimento teórico, como em sua aplicação assistencial, manter adequada articulação biológico-social. No eixo cenário de práticas foram incluídos dois novos vetores: integração docente-assistencial e articulação dos serviços universitários com o SUS. Para o eixo orientação pedagógica, incluiu-se análise crítica da atenção primária à saúde. ${ }^{12}$

Outra iniciativa de articulação entre os ministérios se inspirou no Programa de Educação Tutorial do MEC. Trata-se do Programa de Educação pelo Trabalho para a Saúde que nasce em 2008 como uma das ações criadas com objetivo de fortalecer a atenção primária à saúde, de acordo com os princípios e necessidades do SUS. A educação pelo trabalho, o conceito-chave do projeto, é sua principal estratégia. 0 objetivo geral é fomentar a formação de grupos de aprendizagem tutorial em áreas estratégicas para o SUS, caracterizando-se 
como instrumento para qualificação em serviço dos profissionais, bem como de iniciação ao trabalho e vivências dirigidas aos estudantes das graduações de todos os cursos de saúde. ${ }^{16}$

Entre os objetivos específicos e resultados esperados da proposta estão a integração ensino-serviço-comunidade; a institucionalização das atividades pedagógicas dos profissionais dos serviços de saúde; a constituição de núcleos de excelência em pesquisa aplicada à atenção primária; a satisfação do usuário do SUS; a promoção da capacitação docente dos profissionais dos serviços e o incentivo ao ingresso de profissionais do serviço na carreira docente. ${ }^{16}$

O Programa compõe-se de propostas que são enviadas com participação de Instituições de Educação Superior, públicas ou privadas sem fins lucrativos, que tenham firmado parceria com Secretarias Municipais e/ou Estaduais de Saúde. Permite a participação de docentes, profissionais dos serviços e estudantes dos quatorzes cursos de graduação da área da saúde. O PETSaúde é desenvolvido a partir da aprovação das propostas enviadas, por meio da disponibilização de bolsas para grupos de estudantes, professores e profissionais dos serviços que implementam atividades educativas e pesquisas em unidades do SUS, inicialmente na ESF e, a partir de 2010, nos setores de Saúde Mental e Vigilância à Saúde. Em 2011, MS e MEC lançam novo edital que integra o Pró-Saúde com o PET-Saúde, com intuito de articular as duas estratégias, que até então ocorriam independentes. . $^{14,17,18,19}$

A nova proposta permanece usando a ideia dos mesmos três eixos para a mudança na formação, observando-se algumas diferenças apenas de nomenclatura em relação ao último Pró-Saúde. Dentre as diferenças observadas está a incorporação da discussão da priorização da APS como núcleo coordenador e ordenador do cuidado e à articulação das propostas com as redes de atenção à saúde. ${ }^{19}$

Há muitas aproximações das bases teóricas que constituem as produções enunciativas dos programas acima com a correnteda Vigilância àSaúde. Seu enunciado "orientação do modelo de ensino a partir de estudos clínico-epidemiológicos ancorados em evidências capazes de possibilitar a avaliação crítica do processo de saúdedoença" evoca a ideia trazida pela corrente da necessidade de articulação teóricoprática para o aprofundamento dos avanços da epidemiologia crítica. É a partir dessa articulação que a corrente tem produzido suas propostas de mudança nas formas de organização tecnológica do trabalho em saúde. Define-se que o desenvolvimento do ensino baseado na produção da ciência da epidemiologia e suas interfaces com as produções tecnológicas do trabalho em saúde são considerados potenciais indutores de novos arranjos nas práticas profissionais e de ensino na saúde. . $^{7,8,16}$

O tema da determinação do processo saúde-enfermidade-atenção, muito semelhante à ideia de determinantes de saúde e doença dos programas acima, tem tido forte importância na evolução de conceitos desenvolvidos pela VISAU, principalmente a partir da década 2000 . No mesmo eixo discursivo de valorização da epidemiologia, as produções teóricas têm transitado entre a discussão de modelos epidemiológicos de determinação social e a dimensão da desigualdade social. A corrente propôs o modelo teórico do Modo de Vida e Saúde que define uma estrutura explicativa partindo-se da articulação entre os circuitos dialéticos fundamentais trabalho, reprodução social e modo de vida. Discutese ainda que o papel das desigualdades sociais na produção da doença deve ser compreendido ao se abordar a questão dos estados, processos e eventos, para então, determinar ocorrência, forma e atuação dos gradientes sociais. Dessa maneira, a corrente entende que se deve explorar o 
impacto das desigualdades sociais como determinantes, na qualidade, estilo de vida e nas condições de saúde dos sujeitos. 20,21,22

Outra proposição bastante significativa de tais programas refere-se à prioridade da articulação do ensino com a atenção primária à saúde (APS). As propostas discutem que para a transformação do modelo de ensino é necessário focar-se nos principais problemas de saúde da população valorizando a ESF como principal espaço de integração ensino-serviços. Os modelos assistenciais localizados em espaços-populações concretos na APS são incentivados nas propostas do MS inclusive com a sugestão de constituição de núcleos de excelência em pesquisa aplicada nesta área. ${ }^{7,11,23,25}$

A centralidade da ESF está atrelada à ideia da VISAU de gestão local dos territórios, entendidos como os espaços privilegiados para operações organizadoras dos processos de trabalho em saúde. Portanto, as proposta da VISAU tem balizado o arcabouço teórico da ESF, considerando-a espaço importante para a reorganização da prática médica, clínica, a partir da ampliação de seu objeto de trabalho, passando do indivíduo para a família. ${ }^{7,24}$

Em articulação com a ideia do fortalecimento da APS, os programas analisados propõem que a promoção da integração ensino-serviço-comunidade deve ocorrer no âmbito do desenvolvimento das redes de atenção à saúde. As redes são apontadas como instrumento potente para induzir responsabilização e qualidade, tendo a APS como ordenadora e coordenadora do cuidado. As redes são discutidas pela VISAU por meio do debate da necessidade de desconstrução dos sistemas fragmentados de atenção à saúde, voltados para as situações agudas e agudizações de condições crônicas, para um sistema integrado em redes. ${ }^{19,24}$

Dessa forma, propõem-se redes de atenção, bastante influentes na última proposta do Pro-Saúde e PET-Saúde, como organizações poliárquicas de conjuntos de serviços de saúde, vinculados entre si por uma missão única, por objetivos comuns e por uma ação cooperativa e interdependente, que permitem ofertar uma atenção contínua e integral a determinada população. Tais redes são organizadas em função da epidemia moderna das condições crônicas. ${ }^{18,24}$

\section{A Educar-SUS, Aprender-SUS, VER- SUS e a corrente Em Defesa da Vida}

A Política de Educação e Desenvolvimento para o SUS foi apresentada em 2003 referindo-se que sua produção considerou análise cuidadosa e organizada das iniciativas anteriores no campo do desenvolvimento dos profissionais de saúde, das experiências de mudança na graduação, dos estudos a respeito do processo de especialização em serviço, das experiências de educação popular em saúde e de práticas inovadoras de educação na saúde. Dessa forma, a EducarsUS contemplava concomitantemente políticas na área de formação dos trabalhadores da saúde e de seu desenvolvimento, englobando, portanto, iniciativas no campo da graduação, formação técnica e de pósgraduação, além da educação permanente a partir dos serviços de saúde. ${ }^{26}$

No que diz respeito ao ensino de graduação, buscou-se como eixo estratégico o incentivo à implementação das DCN para os cursos de nível superior da área da saúde. Para tanto, concentrou-se nos seguintes enfoques:

(...) desenvolvimento de estratégias para transformações curriculares na graduação das profissões da saúde; desenvolvimento de currículos integrados; adoção de 
metodologias ativas de ensinoaprendizagem que possibilitassem tomar as práticas e problemas da realidade como mote para a aprendizagem; adoção de metodologias inovadoras de avaliação; diversificação dos cenários de práticas desde o início dos cursos; trabalho em equipe multiprofissional e transdisciplinar, para garantir integralidade e continuidade da atenção e produção de conhecimento relevante para o SUS. ${ }^{27: 49}$

Para o desenvolvimento de tais propostas, o MS propôs a realização de ações específicas para a mudança na graduação: cursos de aperfeiçoamento pedagógico para docentes e profissionais dos serviços; especialização para docentes em educação de profissionais de saúde; implementação das políticas de humanização com participação dos professores e dos estudantes; desenvolvimento de estratégias de articulação multiprofissional e transdisciplinar e desenvolvimento de estágios de vivências no SUS. ${ }^{27}$

Durante a operacionalização da proposta foi lançada em 2004 a AprenderSUS: $O$ SUS $e$ os cursos de graduação na área da saúde, com intuito de dar um passo considerado essencial para a construção de relações de cooperação entre o sistema de saúde e as instituições de educação superior. Partiu-se da ideia de que predomina formação alheia à organização da gestão setorial e ao debate crítico sobre os sistemas de estruturação do cuidado à saúde, e que a graduação nos cursos da área tem permanecido impermeável ao controle social. Dessa forma, buscou-se promover mudanças na formação profissional de modo a aproximá-la dos conceitos e princípios que possibilitassem atenção integral e humanizada à população brasileira. ${ }^{28}$

Nesse contexto, a proposta prevê que a formação não pode tomar como referência apenas a busca eficiente de evidências ao diagnóstico, cuidado, tratamento, prognóstico, etiologia e profilaxia das doenças e agravos, mas ao desenvolvimento de condições de atendimento às necessidades de saúde das pessoas e das populações, da gestão setorial e do controle social em saúde, redimensionando o desenvolvimento da autonomia das pessoas até a condição de influência na formulação de políticas do cuidado. ${ }^{28}$

A integralidade foi 0 conceito estrutural da proposta para as ações que devem nortear as práticas na produção do cuidado, sobretudo no desenvolvimento do trabalho e da educação na saúde, tendo em vista um sistema de saúde usuáriocentrado. Buscou-se provocar interações que garantissem a pluralidade de atores envolvidos, conferindo transversalidade às ações, seja na integração de saberes e práticas que incluíssem a ampliação das práticas clínicas, o conhecimento da realidade, a permeabilidade aos usuários, o acolhimento e responsabilização, vínculo, intersetorialidade, resolutividade $e$ as práticas locais de ensino e saúde. ${ }^{28,29}$

Dentre as ações desenvolvidas pela Aprender-SUS estão: a publicação de convocatória nacional para o desencadeamento da sistematização de práticas inovadoras de integralidade no ensino da saúde; apoio à produção de conhecimento sobre processos de mudança; inclusão de linhas de financiamento para apoiar processos de mudança nas relações institucionais da educação superior com as redes de gestão, de atenção e de controle social do SUS e implantação de laboratórios para o desenvolvimento de práticas integradas. ${ }^{27}$

Além destas ações, buscou-se com os Polos de Educação Permanente em Saúde em 2004, compostos por instâncias colegiadas com participação de gestores, usuários, trabalhadores, docentes e estudantes, a promoção da interinstitucionalidade e participação de diversos atores na 
definição dos projetos de mudança. Em tais espaços, as propostas particulares para a construção de estratégias de mudança no ensino das profissões da saúde, ligados ao fortalecimento do SUS, deveriam ser discutidas e deliberadas. ${ }^{26,28}$

Por fim, desenvolveram-se os estágios de vivência no SUS a partir da aproximação com estudantes da área da saúde. Baseouse em experiências como a da parceria da Secretaria Estadual de Saúde e a Escola de Saúde Pública do Rio Grande do Sul, com os estudantes da área da saúde, que em 2001, desenvolveram os estágios de vivência no SUS. A proposta foi incorporada como projeto político do MS em 2003, que criou, em parceria com diversas executivas e diretórios nacionais de estudantes da área da saúde, o Projeto Vivências e Estágios na Realidade do SUS do Brasil. As vivências se caracterizam por permitir espaços de encontros entre estudantes e determinadas realidades, de modo que os mesmos reflitam sobre ações sociais ali desencadeadas com base nas realidades vividas. ${ }^{30,31,32}$

Apresentam característica de imersão, na qual determinado grupo de estudantes convive por um período de tempo de aproximadamente 15 dias no mesmo espaço físico, compartilhando experiências do contato com a realidade do SUS, com a expectativa de que a cotidianidade imprima marca fundamental à vivência. O VER-SUS/ Brasil tem como objetivo a criação de novas relações de compromisso e de cooperação entre estudantes, gestores de saúde, instituições de ensino superior e movimentos sociais. O Projeto foi interrompido em 2005, sendo reiniciado com apoio da Secretaria de Atenção à Saúde do Ministério da Saúde, da Rede Unida e da Rede Governo Colaborativo em Saúde da Universidade Federal do Rio Grande do Sul em 2011. ${ }^{33,34,35}$

Apresentadas as propostas consideradas parte do mesmo projeto, observa-se que as matrizes discursivas que permeiam seus enunciados aproximam- se do ideário da corrente DV. A ideia de buscar-se formar os profissionais através da construção do atendimento às necessidades de saúde das pessoas e das populações, com desenvolvimento de sua autonomia, aproxima-se do enunciado da corrente de que a gestão de modelos de atenção à saúde deve ter o intuito de ampliar a capacidade resolutiva e promotora de autonomia. A DV propõe que os serviços de saúde, incluindo rede de atenção primária à saúde, unidades hospitalares e outros, sejam espaços onde se garantam a captação e gerenciamento da complexidade das necessidades de saúde, desenvolvendo a autonomia dos usuários até a condição de influência na formulação de políticas do cuidado. ${ }^{8,28}$

A orientação das graduações para a integralidade, apresentada como meta principal das políticas acima, é proposta como um processo que se dá através da aproximação de princípios que possibilitem atenção integral e humanizada à população. Para a DV, a atenção integral se refere, pelo menos, ao reconhecimento da produção de subjetividade; da presença das histórias individuais, coletivas, sociais, familiares e/ou culturais e dos adoecimentos como vivências no andar do processo saúdedoença-cuidado-qualidade de vida. Já a humanização, por sua vez, se refere, pelo menos, à restituição da unidade entre a área científica e a área de humanidades, ciências naturais, entre afetividade, racionalidade cognitivo-instrumental e alteridade e entre razão e emoção. ${ }^{35}$

As categorias cuidado e sistema de saúde usuário-centrado, presentes nas políticas analisadas, são valorizadas pela DV ao discutir a necessidade de que a centralidade da atenção à saúde seja o usuário. Propõe-se que a orientação do cuidado deve ser direcionada para com o outro, não para com os fatores externos ao encontro, como a técnica, a rotina, o protocolo, a profissão ou a instituição, mas para a centralidade no contato com a 
alteridade. Desse modo, a ideia de trabalhar desde a graduação, com noções que buscam fortalecer o cuidado enquanto constituinte de relações de alteridade, aproximam as propostas desenvolvidas pela DV com as últimas políticas em análise. ${ }^{27,36}$

A inclusão de diferentes atores nos processos de construção da reforma sanitária é almejada pela Educar-SUS a partir da visualização da necessidade de articulação de todos os elementos possíveis para criar um contexto de formação mais favorável. Para tanto, propõe a implementação de políticas de humanização com participação dos professores e dos estudantes por meio do desenvolvimento de estratégias de articulação multiprofissional e transdisciplinar e de interação com a rede de serviços, usuários e controle social. ${ }^{5}$

Esta construção se aproxima do conceito do Método Paidéia, proposto pela DV, que discute os coletivos como produtores de valores de uso (bens e serviços) que venham a cumprir, no cotidiano insitucional, articulação e partilhamento de poderes com vistas ao aperfeiçoamento das pessoas e instituições. O método reconhece a importância, a pluralidade e a interpenetração (transversalidade) das instituições, assim como a necessidade de entender esses espaços de produção de subjetividade, passíveis de transformação, como instrumentos para realização de desejos coletivos. ${ }^{37,38,39}$

Teoricamente, a ideia remete ainda ao conceito do quadrilátero da formação para a área da saúde: ensino, gestão, atenção e controle social, desenvolvido pela DV como a possibilidade de relações orgânicas entre as estruturas da gestão sanitária (práticas gerenciais e organização da rede), as instituições de ensino (práticas de formação, produção de conhecimento e cooperação), os órgãos de controle social (movimentos sociais e de educação popular) e os serviços de atenção à saúde (profissionais e suas práticas em espaços universitários ou não, hospitalares ou não). ${ }^{40}$
Por fim, o conceito de cadeia de cuidado progressivo à saúde, encontrado na Educar-SUS, assemelha-se ao de linhas de cuidado proposto pela DV. As linhas de cuidado propõem que as intervenções ocorram em toda a cadeia de produção da saúde, desde a promoção, prevenção, vigilância, assistência e reabilitação. Tal cadeia, além de ser constituída na atenção à saúde, perpassa pelo campo da gestão, articulando intervenções desde - equacionamento de tecnologias a medidas de regulação. No que diz respeito à integralidade, a linha de cuidado opera a partir do conceito de cuidado, o qual é capaz de impactar o processo de saúde e doença partindo do lugar singular do encontro que só o trabalho vivo pode dar conta. ${ }^{26,41}$

\section{Considerações Finais}

O desenvolvimento de políticas públicas com objetivo de incentivar mudanças na educação dos trabalhadores da saúde tem tido grande importância no Brasil. A articulação com as transformações propostas pelo SUS e pela reforma sanitária brasileira é um movimento de intensa produção de inovação para os campos da saúde e da educação. A construção de propostas é atravessada por projetos que disputam modos de entender e agir sobre a produção do cuidado e atenção à saúde, e consequentemente, dos modelos de atenção à saúde e de educação.

Mesmo reconhecendo toda riqueza e extensão da produção da Saúde Coletiva, que não se esgota nesse debate, a análise das matrizes discursivas permitiu compreender o contexto de sua produção discursiva em interface com políticas de incentivo à mudança na formação em saúde. As propostas de governo não estão vinculadas a modelos pré-determinados, mas revelaramse como potentes experimentadoras e 


\section{Artigo Original}

construtoras de proposições teóricopráticas para a mudança no ensino dos trabalhadores.

As diferentes políticas de mudança e suas redes de relações enunciativas se encontram no cerne do movimento macro e micropolítico das reformas sanitárias desencadeadas no Brasil. São fruto de toda articulação teórico-prática e política para a produção de um modelo de atenção à saúde contrário ao biomédico, centrado no biologicismo, discurso assimilado por ambas as correntes da Saúde Coletiva estudadas. Nesse jogo discursivo, a produção de consensos, entre os diferentes modos de ver o campo, perpassa pela comum demanda da sociedade brasileira por um sistema de saúde que promova a integralidade e que seja universal e equitativo.

Ressalta-se ainda, que, mesmo podendo-se encontrar trechos discursivos que são claramente apresentados nos enunciados das políticas de mudança no ensino das profissões de saúde, nas suas inter-relações com as correntes de pensamento da Saúde Coletiva, deve-se compreender que sempre há dinamicidade na produção de discursos e práticas no cotidiano das políticas sociais em seus locos de desenvolvimento. Os efeitos e resultados das políticas aqui analisadas são múltiplos, pois se desenvolvem em contextos singulares nos mais diversos cenários de produção da educação, cuidado, gestão e participação no âmbito do SUS. As escolas possuem processos internos de debate e formulação curricular e, quando acionadas pelas propostas de governo, disputam as produções a partir de seus interesses e necessidades.

Por fim, reitera-se que as relações entre enunciados não podem ser inteiramente separadas, como se fossem dissecadas, sem levar em conta a constituição subjetiva e atemporal dos desejos dos sujeitos que as produzem, mesmo que sejam úteis para o debate e avaliação das inovações no campo da formação de trabalhadores da saúde.

\section{Referências}

${ }^{1}$. Feuerwerker LCM, Sena RR. Contribuição ao movimento de mudança na formação profissional em saúde: uma avaliação das experiências UNI. Interface (Botucatu), fev. 2002; 06(10): 37-50.

2. Feuerwerker LCM, Marsiglia R. Estratégias para mudanças na formação de RHs com base nas experiências IDA/UNI. Divulg. Saude Debate, jul. 1996; 12(1): 24-28.

3. Brasil. Assembleia Constituinte. Constituição da República Federativa do Brasil de 1988. Brasília: MP, 1988.

4. Brasil. Presidência da República. Lei no 8.080 de 19 de setembro de 1990. Diário Oficial da União 1990; 19 set.

5 . . Decreto no. 4.726, de 9 de junho de 2003. Diário Oficial da União 2003; 9 de jun.

${ }^{6}$. Foucault M. A ordem do discurso. São Paulo: Graal, 1972.

7. Teixeira CF. A Mudança do modelo de atenção à saúde no SUS. Desatando nós, criando laços. Saúde debate, Rio de Janeiro, set./dez. 2003; 27(65): 257-277. 


\section{Artigo Original}

${ }^{8}$. Carvalho SR. Saúde coletiva e promoção da saúde. São Paulo: Hucitec, 2005.

9. Merhy EE. Em busca do tempo perdido: a micropolítica do trabalho vivo em ato, em saúde. In. Merhy EE, Onocko R. (Org.). Agir em Saúde: um desafio para o público. São Paulo: Hucitec, 1997: 75-130.

${ }^{10}$. Oliveira NA et al. Mudanças Curriculares no Ensino Médico Brasileiro: um Debate Crucial no Contexto do Promed. Rev. Bras. Educ. Méd., Rio de Janeiro, jul./set. 2008; 32(3): 333-346.

${ }^{11}$. Brasil. Ministério da Saúde. Ministério da Educação. Projeto de Incentivo a Mudanças Curriculares nos Cursos de Medicina. Brasília: Ministério da Saúde, 2001.

12. Brasil. Ministério da Saúde. Programa Nacional de Reorientação da Formação Profissional em Saúde. Brasília: Ministério da Saúde, 2005.

13. _ Programa Nacional de Reorientação da Formação Profissional em Saúde: objetivos, implementação e desenvolvimento potencial. Brasília: Ministério da Saúde, 2007.

14. . Portaria interministerial no 3.019, de 26 de novembro de 2007. Diário Oficial da União 2007. 26 de nov.

15. Carvalho YM, Ceccim RB. Formação e educação em saúde: aprendizados com a saúde coletiva. In: Campos GWS et al., (Org.). Tratado de Saúde Coletiva. São Paulo: Hucitec; Rio de Janeiro: Fiocruz, 2006: 137-170.

${ }^{16}$. Brasil. Portaria Interministerial no 1.802, de 26 de agosto de 2008. Institui o Programa de Educação pelo Trabalho para a Saúde - PET-Saúde. Diário Oficial da União 2008. 26 de ago.

17. _. Portaria Conjunta no 3, de 3 de maço de 2010. Institui no âmbito do Programa de Educação pelo Trabalho para a Saúde (PET Saúde), o PET Saúde/Vigilância em Saúde. Diário Oficial da União 2010. 3 de mar.

${ }^{18}$. _. Portaria Conjunta no 6, de 17 de setembro de 2010. Institui no âmbito do Programa de Educação pelo Trabalho para a Saúde (PET Saúde), o PET Saúde/Saúde Mental. Diário Oficial da União 2010. 17 de set.

19. Portaria Interministerial no 421, de 3 de março de 2010. Institui o Programa de Educação pelo Trabalho para a Saúde (PET-Saúde) e dá outras providências. Diário Oficial da União 2010. 3 de mar.

20. Edital no24 de 15 de dezembro de 2011. Seleção de projetos de instituições de educação superior. Diário Oficial da União 2011. 15 de dez

21. Almeida-Filho N. Modelos de determinação social das doenças crônicas não-transmissíveis. Ciênc. saúde coletiva, Rio de Janeiro, out./dez. 2004; 9(4): 865-884.

22 . - A problemática teórica da determinação social da saúde: nota breve sobre desigualdades em saúde como objeto de conhecimento. Saúde debate, Rio de Janeiro, set./ dez. 2009; 33(83): 349-370. 


\section{Artigo Original}

23. Brasil. Ministério da Educação. Secretaria de Educação Superior. Programa de Educação Tutorial: apresentação. (Texto da Internet). 2013. Disponível em <http://portal.mec.gov. $\mathrm{br} /$ index.php?option=com_content\&view $=$ article\&id=12223\&ativo $=481 \& /$ temid $=480 />$. Acessado em: 16 mar 2013.

24. Mendes EV. As redes de atenção à saúde. Ciênc. saúde colet., Rio de Janeiro, v.15, n. 5, p. 2297-2305, ago. 2010.

25. Mendes EV. (org.) A Vigilância à Saúde no Distrito Sanitário. Brasília: OPAS/MS, 1993. (Série de Desenvolvimento de Serviços de Saúde).

26. Brasil. Política de Educação e Desenvolvimento para o SUS: Caminhos para a Educação Permanente em Saúde. Pólos de Educação Permanente em Saúde. Ministério da Saúde: Brasília, 2003.

27. Brasil. Ministério da Saúde. Secretaria de Gestão do Trabalho e da Educação na Saúde. Departamento de Educação na Saúde. Aprender-SUS: o SUS e os cursos de graduação na área da saúde. Brasília: Ministério da Saúde, 2004.

28 . - Convocatória para apresentação de experiências de ensino na formação de profissionais para a integralidade em saúde. Brasília: Ministério da Saúde, 2004.

29 . . VER-SUS Brasil: Caderno de Textos. Brasília: Ministério da Saúde, 2004.

30 Projeto de Vivências e Estágios na Realidade do Sistema Único de Saúde do Brasil: Caderno de Textos. Brasília, 2004, 299 p. (Textos Básicos de Saúde, Série B).

31. Portaria no 198 de 13 de fevereiro de 2004. Diário Oficial da União 2004. 12 de fev.

32. Torres OM. Os estágios de vivência no Sistema Único de Saúde: das experiências regionais à (trans)formação político-pedagógica do VER-SUS-Brasil. 2005. Dissertação (Mestrado Profissionalizante) - Instituto de Saúde Coletiva, Universidade Federal da Bahia, Salvador, BA. 2005.

33. Projeto Vivências e Estágios na Realidade do SUS: apresentação. 2013 [texto da internet]. Disponível em <http://versus.otics.org/versus-1/apresentacao>. Acessado em: 14 jan. 2013.

34. Ceccim RB, Bilibio LFS. Observação da educação dos profissionais da saúde: evidências à articulação entre gestores, formadores e estudantes. In: Brasil. Ministério da Saúde. Observatório de Recursos Humanos em Saúde no Brasil: estudos e análises. Rio de Janeiro: FIOCRUZ, 2003: 343-372.

35. Ceccim RB, Capozzolo AA. Educação dos profissionais de saúde e afirmação da vida: a prática clínica como resistência e criação. In: Marins JJN et al (Org.). Educação médica em transformação: instrumentos para a construção de novas realidades. São Paulo: Hucitec, 2004: 346-390.

${ }^{36}$. Ceccim RB, Merhy EE. Um agir micropolítico e pedagógico intenso: a hu manização entre laços e perspectivas. Interface (Botucatu), 2009; 13, supl.1: 531-342.

37. Campos GWS. Saúde Paidéia. São Paulo: Hucitec, 1997. 3ed. 


\section{Artigo Original}

38. . Efeito Paidéia e o campo da saúde: reflexões sobre a relação entre o sujeito e o mundo da vida. Trab. educ. saúde, Rio de Janeiro, mar. 2006; 4(1): 19-31.

39. Campos GWS, Domitti AC. Apoio Matricial e equipe de referência: uma metodologia para gestão do trabalho interdisciplinar em saúde. Cadernos de Saúde Pública. Rio de Janeiro, fev. 2007; 23(2): 399-407.

${ }^{40}$. Ceccim RB, Feuerwerker LCM. O quadrilátero da formação para a área da saúde: ensino, gestão, atenção e controle social. Physis, Rio de Janeiro, jan./jun. 2004; 4(1): 41-65.

41. Malta DC, Merhy EE. O percurso da linha do cuidado sob a perspectiva das doenças crônicas não transmissíveis. Interface (Botucatu), set. 2010; 14(34): 593-606. 